\title{
Risk and Capital Management in Insurance Companies
}

\author{
Nikolaus von Bomhard \\ Munich Re, Königinstrasse 107, München 80802, Germany. \\ E-mail: dscheckenbach@munichre.com
}

This article is reasoning why risk and capital management in insurance companies malfunctioned partially during the recent capital market crises and what measures insurers and regulators have to adopt to ameliorate thoroughly their control and steering systems. Comparisons to finance and banking are made throughout the article, because they are Instructive and rich in contrast.

The Geneva Papers (2005) 30, 52-59. doi:10.1057/palgrave.gpp.2510008

Keywords: insurance risk management; capital management; Solvency II; asset/liability management

\section{Introduction}

The objective of this article is to highlight the origins of the malaise in the area of risk and capital management in the insurance industry that was observed in the period of the capital markets crisis of 2001-2003 and to sketch the measures necessary to overcome it. The objective is not to conduct an in-depth research on one of the subjects treated. Therefore, no distinction is made between insurance and reinsurance, although we are aware of the fundamental differences between the two, especially under the accounting and regulatory points of view. Geographically, the focus is set on Europe, but many of the assertions are valid for the insurance industry in general.

Much will be said about banking because the comparison with the business, risk management and regulation of banks helps in understanding the challenges that insurers and their regulators face, as well as the origins of many new trends in the insurance world. This article also asserts that bankers are not superior risk managers but rather that they started developing a serious risk management culture earlier and that the risks in banking are somewhat more readily contained within a clearly defined framework than at least some of the risks arising in insurance.

\section{Some spotlights on the development of banking regulation}

During the crisis of 2001-2003, the risk management of the finance industry in general underwent a critical examination by the capital markets. Falling and highly volatile equity markets, low interest rates and some major industry insolvencies such as Enron and Parmalat made investment management in insurance companies an unenviable job in those years. But history teaches us much about the future, and if, in general, banks weathered these turbulent conditions better than insurance companies, then perhaps the history lesson in that sector came much earlier and in some cases at a much heftier price. 
In 1974, in the aftermath of the bankruptcy of the German Herstatt Bank, the Basel Committee on Banking Supervision was founded under the auspices of the Bank of International Settlements (BIS) with the intention of creating international standards for banking regulation and as such the famous "level playing field" for the competition of banks of different countries. ${ }^{1}$ The Basel Committee has no supranational supervisory authority or legal power. Nonetheless, its recommendations are observed by its member countries.

The Basel Capital Accord of 1988 set a framework for the measurement of credit risks and defined minimum capital adequacy requirements. The Accord was amended in 1996 to incorporate market risks and - importantly - to allow for the use of (sufficiently back tested) internal models for the allocation of risk capital for market risk. ${ }^{2}$ Currently, a new amendment, Basel II, is under way to adopt more risk-sensitive minimum capital requirements for banking organizations.

Not only were the regulatory bodies active in developing more sophisticated risk management practices, but the banks themselves heavily invested time, money and staff in refining their methodologies and procedures for risk management. ${ }^{3}$ They did this for two reasons:

- The first, and most obvious reason, is that risk management is vital for securing the future of the financial firm.

- Secondly, banks realized that they could save precious risk capital by developing more sophisticated internal models for risk management that supported more representative, and hopefully lower, risk exposures than the standard model as prescribed by the Basel Committee.

However, none of this prevented the spectacular fall of the breed of the Barings Bank, Long Term Capital Management or the Allied Irish Bank. Nonetheless, after 30 years of effort to establish sound principles for risk and capital management in banking, it is perhaps not surprising that the banks managed better during the recent downturn of the capital markets.

\section{Regulation in the insurance industry: convergence towards financial paradigms}

There is no comparable organization to the Basel Committee in the world of insurance and therefore regulation in this area is highly incongruent.

\footnotetext{
${ }^{1}$ There is clearly also a political side to the story. Superficially, the U.S. banks seemed to regard the Japanese banks as undercapitalized and hence were concerned about their unfair competitive advantage. While elements of these protectionist arguments prevailed in the reasons behind the adoption of the Basel Accord, the fact is that the Japanese banks were indeed undercapitalized and the Accord represented a major milestone for the achievement of improved stability in the international financial system.

2 More on this point later.

${ }^{3}$ Beside this, the quest for a more efficient capital management favoured the development of completely new markets and instruments, such as collateralized loan obligations (CLOs) and synthetic CLOs. With these instruments banks are able to lay off credit risks from their balance sheet and in so doing to free up risk capital. It remains to be seen whether Solvency II and fair value accounting will make insurance linked securities ("cat bonds") similarly attractive for insurance and reinsurance companies.
} 
Let us take a closer look at the regulation in the European Union. Several directives concerning life insurance have been adopted since 1979. These were purged and summarized by the 2002 directive. Yet considerable flexibility is still left to the national supervisory authorities as to how to implement the directive. For example, discount rates for the calculation of technical provisions or valuation of assets have to be calculated prudently, but no further specification is offered. More guidance is given for the calculation of solvency and the diversification of asset portfolios. In 2002, a directive for non-life insurance was also adopted, which has many features in common with the life insurance directive.

The European legislator clearly appears to be desirous of a "Basel Committee on Insurance Supervision". It is the explicit intention of the envisaged Solvency II project to create a regulatory framework for insurance companies in the spirit of the Basel Committee, and in that respect it is far more ambitious than all the previous European directives in this field. It will embrace a vast area of subjects like asset/liability management, reinsurance arrangements and techniques from the world of financial economics. The use of internal models will be considered, which could encourage the insurance industry to strive for a more sophisticated risk culture, just as the 1996 amendment of the Basel Accord succeeded in doing in banking. Eventually, the Solvency II project will have to be seen in conjunction with the initiatives of the IASB on fair value accounting. The aim is to represent as closely as possible the economic situation of an insurance company and set regulations that are in line with the economic needs. ${ }^{4}$

\section{The insurance industry since the late 1990s: enhancement of risk management}

In 1994, the European Union deregulated the market for non-life insurance, and this immediately placed considerable competitive pressure on the industry. Additionally, the strong performance of the financial markets strengthened the capital position of the insurers. The high competition plus high capacities could not but lead to one consequence: inadequate premiums.

Life insurance companies were in a much more comfortable situation. In Europe, the increasing concerns about the security of the pay-as-you-go state systems expanded the premium income of insurers dramatically. From 1997 to 2000 premiums grew by 12 per cent on an annualized basis! This expansion was fuelled additionally by the tax advantages that are granted to life insurance contracts in many European countries. However, the most prominent incentive to buy life insurance in this period was the rocketing capital market.

In Germany, the situation can be summarized as follows. From 1995 until mid-2000 the so-called guaranteed interest rate was at c. 4 per cent, whereas from 1995 to 1998 the yield of 10-year Bunds fell from around 8 per cent to below 4 per cent! What is more, from 1994 to 1999 the industry average spread of bonus rates granted to policy

\footnotetext{
${ }^{4}$ However, an observer could be forgiven for thinking that this aim is sometimes lost in the myriads of transitional arrangements and compromises that have been negotiated by the various stakeholders in the most recent past.
} 
holders over the 10-year Bund yield increased from 45 to 325 bps. In every respect, one can say that German life insurance companies declared far more than they could possibly achieve with risk-less investments.

Since competition on the German market was dominated by the level of the bonus rate, insurance companies geared their equity exposure more and more towards attaining higher bonuses and attracting more premiums: In hindsight, some insurance companies took risks on the asset side in an uncontrolled way.

To the defence of the insurance industry it has to be said that insurers were not the only participants to be affected by the equity market crisis. Some economists and analysts argued that price/earnings ratios had lost their relevance in the new economy. In February 2000, the price/earnings ratio of Cisco Systems, the flagship of the new economy, surpassed the value of 200.

Competition and the stock market bubble do not fully explain the partly inadequate risk control in the insurance industry, however. The other reasons, in fact, lie deeper:

- There were insufficient incentives for setting meaningful (i.e. risk-based) minimum standards for risk and capital management, both nationally and internationally. Consequently, there was little pressure or incentive for insurance companies from the regulatory side in this direction.

- Corporations, as well as individuals, or even governments tend to "slacken the reins" in times of prosperity. This was also clearly the case (with the benefit of hindsight) in the relatively overcapitalized insurance industry.

- Another important but often unmentioned reason is the parallel universes of traditional actuarial thinking that prevailed in insurance companies and the financial economic thinking that prevailed in banks. ${ }^{5}$

\section{Asset and liability management}

In this area, perhaps more than any other, it is instructive to look to the banking world. There are clearly some distinct differences between assets and liabilities on the bank balance sheet (e.g. the emergence of credit risk). Yet it remains true that in many respects such as interest rate sensitivity, assets and liabilities are, broadly speaking, of the same nature. From an interest rate risk perspective, the difference between a loan and a deposit is merely the algebraic sign. Additionally, bankers usually work on both sides of the balance sheet. Think of a money market operator who is accepting and offering short-dated deposits and loans. As a consequence, the similar nature and the broad understanding of the business of both sides of the balance sheet makes asset/ liability management for banks relatively easier than for insurance companies. Bankers can identify many risk factors that drive both sides of the balance sheet and have instruments on hand to effectively influence those factors. ${ }^{6}$ It is not surprising that the no-arbitrage concept was invented in the world of financial markets.

\footnotetext{
${ }^{5}$ We return to look at this issue in more detail shortly.

${ }^{6}$ The most striking example is the interest rate swap. Traditional banking business consists in taking on short-dated deposits (e.g. savings deposits) and offering long-dated loans (e.g. mortgages). The emerging open interest position is exactly offset by a payer swap. Use of this simple interest rate instrument could have prevented the severe U.S. Savings \& Loans crisis in the 1980s from happening!
} 
How is the situation in the insurance industry different? Actuaries and financial engineers are (or at least were) of different worlds. Many fundamental subjects such as interest rates, risk or value have a different colour in actuarial or financial science. But beyond culture and science, the instruments and risks on the asset and liability side of an insurer's balance sheet are fundamentally different, and to make the situation even more complicated, the instruments and risks in life insurance are different from those in non-life insurance.

The management of an insurance company has therefore to deal with and understand businesses and risks of a very heterogeneous nature. This is particularly true for that entity within an insurance company in which assets meet liabilities: the asset/liability management unit. This unit should ensure that the strategic allocation of the assets takes account of the characteristics of the liabilities. This includes the dependency structure between asset and liability cash flows as well the businesses' liquidity requirements (or as is often the case in insurance, the lack thereof).

\section{The insurer's challenge}

The disparate nature of assets and liabilities (and indeed the often indirect linkages between the two) causes a number of further problems, which an insurance company as well as its regulator must resolve.

\section{Making different risk measurements commensurate}

It is necessary to make the measurement of the risks arising on the two sides of the balance sheet (e.g. longevity, Nat Cat risk and market risk) as commensurate as possible. On the asset side, Value at Risk became commonly accepted as a risk measure whereas on the liability side today regulators increasingly favour tail value at risk (or expected shortfall) measures. In life insurance the critical issue is the period for measurement of risk. Making all risk measures completely commensurate may be useful for some limited applications (e.g. for the purpose of calculating a diversification benefit) but is of itself of little value for steering purposes. The challenge for the insurer's risk management unit is to achieve consistency without losing its relevance to the business units.

\section{Capital allocation}

As a consequence of the capital markets crisis of 2001-2003, capital became a scarce resource within the formerly well and often overcapitalized insurance industry. It is therefore not surprising that in the last years intensive research was dedicated to how risk capital can be allocated in a fair way to different operating entities and lines of business. The multiple downgrades conducted by rating agencies further increased the pressure on some insurers to act. Only if risks are robustly measured is it possible to set benchmarks that treat the different business lines and affiliates in different jurisdictions in a fair way, and only then is it possible to detect value-creating and 
value-destroying businesses and to formulate appropriate strategic responses around these insights.

\section{Accounting and statutory reporting}

Unfortunately, the true economic quality of the various types of businesses is often obfuscated by the different regimes of accounting and statutory reporting. Life insurance, non-life insurance and investments are very often subject to different rules that also differ from country to country. For example, life liabilities may be discounted at market rates or at lower and more prudent interest rates, whereas even for long-tail business non-life liabilities may not be discounted at all. However, as stated above, Solvency II and fair value accounting should, at least in Europe, eventually remedy this situation.

\section{Prudent underwriting}

Insurers have to base their business rigorously on prudent risk assumptions. Technical prices, expenses and return requirements on risk capital must not be regarded as desirable to attain, but as part of the minimum price. In the case of life insurance, this implies that guarantees to policy holders have to be priced according to the standards used in banking. ${ }^{7}$ For reinsurers it is also vital to simultaneously ground the business model in solid client relationships. ${ }^{8}$

\section{Accumulation control}

On the liability side, insurers have had in place for a long time highly sophisticated and efficient control mechanisms to measure their accumulated exposures to natural catastrophic perils, for example, wind storms in Europe, earthquakes in California, etc.; and on the asset side counter party credit risk exposures have been routinely measured, aggregated and limited.

However, the tragic and unthinkable events of 11 September 2001 awakened in all of us the stark shortcomings of managing accumulations on a single peril basis. While many industry commentators often spoke academically of the need to consider cross line of business and cross balance sheet exposures, few had mechanisms in place that captured this need. It is also worthwhile to note that no prior event, which caused catastrophic insurance losses, had such a noticeable impact on the capital markets. ${ }^{9}$

\footnotetext{
${ }^{7}$ That is, using market consistent pricing techniques.

${ }^{8}$ A critical remark on shareholders' expectations and their advocates: the analysts. Analysts as all other market participants live not beyond the Zeitgeist. At one time they praised the strategy of insurance companies with high equity investments. This strategy turned out to be rather risky in the period 20012003. If some analysts today recommend to reinsurers an opportunistic underwriting approach at all costs to make their business more profitable, they risk overlooking the simple fact that the franchise value of a reinsurer is built up from solidifying client relationships.

${ }^{9}$ For example, of the three major natural catastrophes, Northridge earthquake, Hurricane Andrew and the Kobe earthquake, only the latter had some measurable impact on the stock market: In the week following the earthquake, the Nikkei 225 index fell 8 per cent (which is all but an outlier) and partly recovered in the following week.
} 
In light of this, insurers should strive now for even more comprehensive methodologies to measure accumulations. Single events can involve more than one business line; for example, an accident in an industrial plant can give rise to losses in property, employers' liability, workers' compensation, business interruption, environmental liability, marine and agriculture lines. Since the insurer may also invest in the outstanding equities and bonds of a firm that has purchased from it major property or liability damages cover, the investment portfolios of an insurer could be at risk too. Insurers need to understand thoroughly how single events can cause accumulated losses on both sides of the balance sheet. Of course, there are accumulation risks in life insurance as well. This is especially made evident in the light of terrorism threats or acts involving large office buildings or other infrastructure (e.g. subways).

\section{Hedging}

If the characteristics of the assets of an insurance company were to match the characteristics of the liabilities perfectly, then no hedging actions on the asset side would be necessary, since the overall risk position of the company would already be minimal. In practice, though, the real asset allocation will deviate from the theoretical risk minimizing asset allocation for the following key reasons.

- Insurance is a stochastic process and it is generally impossible to find assets that provide a perfect match to the liabilities in every important dimension.

- Insurers may see scope for the generation of surplus returns on assets.

- Constraints may arise from the regulatory or accounting regime making hedging desirable for minimizing the volatility of shareholders' equity.

Static hedges might then be necessary to neutralize undesirable risk features of the strategic asset allocation, whereas dynamic hedging strategies may have to be implemented to provide inter-temporal protection of the portfolio in times of high market volatility.

However, risks on the liability side can be hedged using capital market traded instruments too. For example, life insurers in the U.K. hedged their guaranteed annuity options with interest rate derivatives - either outright or wrapped in reinsurance treaties - and similar activities were to be seen in Denmark and France.

In non-life insurance, long tail business (such as workers' compensation) that has claims which are driven by inflation also merit attention in hedging considerations. Assets that appreciate with inflation, such as inflation-linked bonds or equities, could be used to (at least partially) compensate for the effect of higher than expected inflation on claim costs. However, regulatory or accounting constraints may require some protection from downside risks.

\section{Conclusion}

Some have said that the capital markets made and withdrew the riches of insurers. Although perhaps too simplistic, what is undeniable is that the capital markets crisis of 2001-2003 has shaken up the insurance industry and its regulators like perhaps no 
other event has in the recent past. It has prompted insurers to take a fresh look at their people, tools and processes in the areas of risk and capital management.

There are important challenges for the industry in the areas of asset and liability management, consistent risk measurement, meaningful capital allocation, reconciling the accounting and statutory views of risk and capital, strict underwriting and technical pricing, accumulation control and hedging of risks on both sides of the balance sheet.

Much can be learned from the banking world - which has a head start on the insurance industry - and some of the methods and paradigms, firmly rooted in financial economics, can be adapted and adopted by insurers.

With the growing recent establishment of the function of the Chief Risk Officer in insurance companies globally - a function that is often tasked with integrating these risk management practices - there are encouraging signs that the industry is indeed rising to the challenge. The 30 -year headstart of the banking industry may soon be little more than a piece of historical trivia. 